\title{
Subepithelial tunneling endoscopic resection with intratunnel morcellation for a giant esophageal leiomyoma
}

Subepithelial tunneling endoscopic resection is an accepted minimally invasive therapy for esophageal subepithelial tumors arising from the muscularis propria layer [1]. Subepithelial tunneling endoscopic resection is highly successful for subepithelial tumors $<4 \mathrm{~cm}$. Larger lesions pose technical challenges for this procedure and for specimen delivery with resultant inferior outcomes [2]. Several techniques have been described to overcome this problem, such as doubleopening subepithelial tunneling endoscopic resection, intracorporeal morcellation, or a thoracoscopy-assisted approach [2-5]. This video demonstrates subepithelial tunneling endoscopic resection for a giant esophageal leiomyoma with intratunnel morcellation.

A 37-year-old man presented with dysphagia. Computed tomography (CT) scan, esophagogastroduodenoscopy (EGD), and endoscopic ultrasound (EUS)-guided fine needle biopsy confirmed a muscularis propria layer leiomyoma at $22 \mathrm{~cm}$ measuring $6.5 \times$ $2.5 \times 4 \mathrm{~cm}$ (>Fig. 1, > Fig. 2). Subepithelial tunneling endoscopic resection was performed ( $\vee$ Video 1 ). After submucosal elevation, a mucosal incision was made at $17 \mathrm{~cm}$ using a triangular tip TT-J knife (Olympus, Tokyo, Japan) and Endocut current (Erbe Vio 200D; Erbe, Tübingen, Germany). The subepithelial tumor was enucleated by generous lateral and forward dissection using forced coagulation current (Erbe). Hemostasis was achieved using a Coagrasper (Olympus). Care was taken to maintain an intact capsule around the leiomyoma. The lesion was too bulky to be delivered en bloc from the tunnel. Therefore, intratunnel morcellation was performed and morcellated tumor fragments were retrieved from the tunnel and esophagus ( $>$ Fig.3). The mucosal incision was closed using endoclips. The procedure time was $210 \mathrm{~min}$. The patient was maintained nil orally for 48 hours followed by an oral diet and was dis-
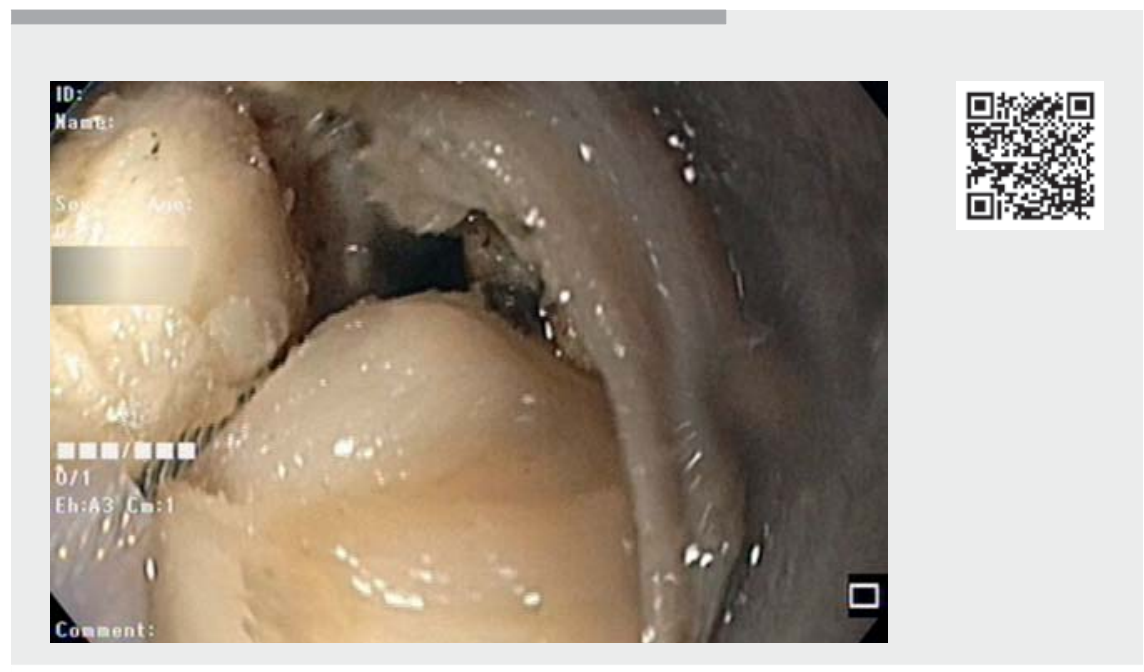

Video 1 This narrated video demonstrates the technique of subepithelial tunneling endoscopic resection for a giant esophageal leiomyoma followed by intratunnel morcellation of the specimen to facilitate specimen delivery.

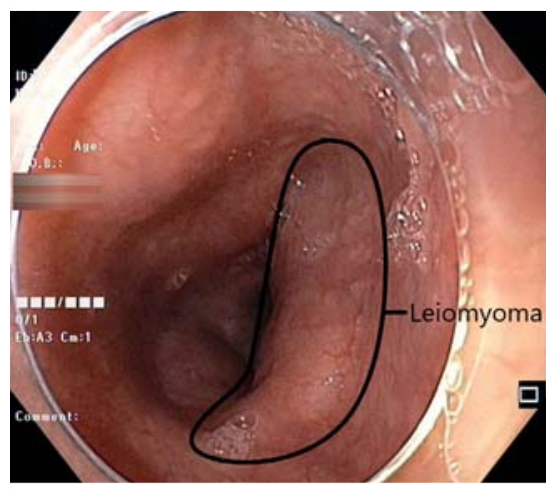

- Fig. 1 Endoscopic view of subepithelial esophageal tumor (outline marked).

charged on day 6 . No adverse events were recorded ( $>$ Fig.4). Final histopathology confirmed leiomyoma. Followup EGD at 4 weeks revealed a healthy scar (\$ Fig.5). The patient reported dysphagia resolution.

This video highlights the importance of intratunnel morcellation to facilitate specimen delivery after subepithelial tunneling endoscopic resection. It also highlights the importance of a preprocedural EUS-guided fine needle biopsy to con-

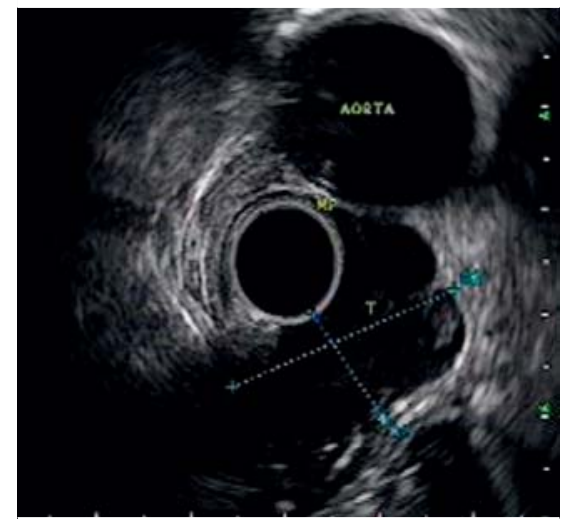

- Fig. 2 Radial endoscopic ultrasonography view of the esophageal subepithelial tumor. Note the aorta in close relation to the tumor.

firm the tumor is benign, because only then could we perform morcellation. In conclusion, subepithelial tunneling endoscopic resection with intratunnel morcellation is a safe and effective technique for resection of a giant esophageal leiomyoma.

Endoscopy_UCTN_Code_TTT_1AO_2AN 


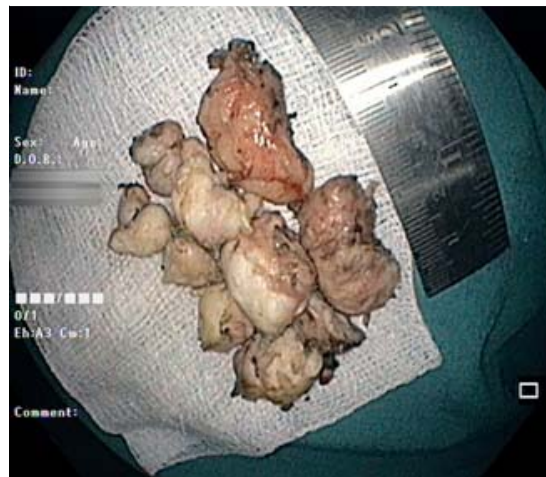

- Fig. 3 External view of the final resected specimen showing the morcellated tumor fragments.

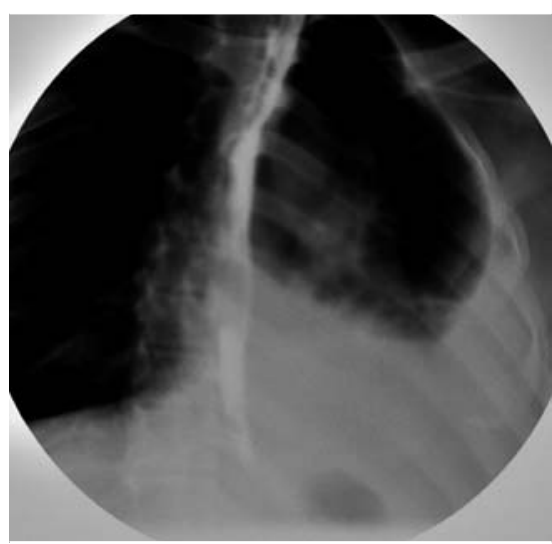

- Fig. 4 Post-operative contrast swallow demonstrating no leak of contrast from the esophageal lumen.

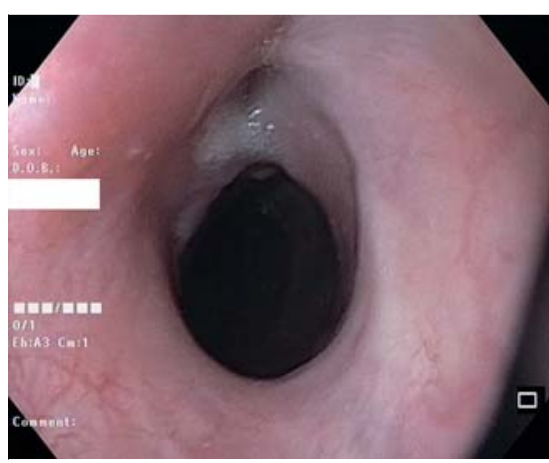

- Fig.5 Endoscopic view of healed site scar on follow-up endoscopy at 4 weeks.

\section{Competing interests}

The authors declare that they have no conflict of interest.

The authors

Ashish Gandhi ${ }^{1}$, Siddharth Dharamsi ${ }^{1}$, Harsh Bapaye $^{2}$, Amol Bapaye ${ }^{1}[$

1 Shivanand Desai Center for Digestive Disorders, Deenanath Mangeshkar Hospital and Research Center, Pune, India

2 Byramjee Jeejeebhoy Medical College, Pune, India

\section{Corresponding author}

\section{Amol Bapaye, MD}

Shivanand Desai Center for Digestive Disorders, Deenanath Mangeshkar Hospital and Research Center, Erandwane, Pune 411004, India amolbapaye@gmail.com

\section{References}

[1] Xu MD, Cai MY, Zhou PH et al. Submucosal tunneling endoscopic resection: a new technique for treating upper GI submucosal tumors originating from the muscularis propria layer (with videos). Gastrointest Endosc 2012; 75: 195-199. doi:10.1016/j. gie.2011.08.018

[2] Bapaye A, Korrapati SK, Dharamsi S et al. Third space endoscopy: lessons learnt from a decade of submucosal endoscopy. J Clin Gastroenterol 2020; 54: 114-129. doi:10.1097/MCG.0000000000001296

[3] Zhang Q, Cai JQ, Xiang L et al. Modified submucosal tunneling endoscopic resection for submucosal tumors in the esophagus and gastric fundus near the cardia. Endoscopy 2017; 49: 784-791. doi:10.1055/s-0043111236
[4] Du C, Linghu E. Submucosal tunneling endoscopic resection for the treatment of gastrointestinal submucosal tumors originating from the muscularis propria layer. J Gastrointest Surg 2017; 21: 2100-2109. doi:10.1007/s11605-017-3579-7

[5] Zhong YS, Shi Q, Guo WG et al. Thoracoscope assisted tunnel endoscopic resection for esophageal SMT from the muscularis propria. Zhonghua Weichang Waike Zazhi 2012; 15: 404-405

\section{Bibliography}

Endoscopy 2022; 54: E364-E365

DOI 10.1055/a-1529-5283

ISSN 0013-726X

published online 9.8.2021

(c) 2021. Thieme. All rights reserved.

Georg Thieme Verlag KG, Rüdigerstraße 14, 70469 Stuttgart, Germany

\section{ENDOSCOPY E-VIDEOS}

https://eref.thieme.de/e-videos

口回 Endoscopy E-Videos is an open access online section, 回触: reporting on interesting cases and new techniques in gastroenterological endoscopy. All papers include a high quality video and all contributions are freely accessible online. Processing charges apply (currently EUR 375), discounts and wavers acc. to HINARI are available.

This section has its own submission website at https://mc.manuscriptcentral.com/e-videos 